\title{
Sandra Lauderdale Graham. Um outro olhar sobre a escravidão e o gênero no Brasil: Caetana diz não: história de mulheres da sociedade escravista brasileira
}

Andréa Lisly Gonçalves

UFOP

São Paulo: Companhia das Letras, 2005, 289p.

A história da cafeicultura no Vale do Paraíba, no Rio de Janeiro, tem em Francisco Peixoto de Lacerda Werneck, o Barão do Pati do Alferes, uma de suas figuras mais representativas. Amparado em sua experiência como proprietário de fazendas e escravos, serviu-se da pena para divulgar seus conhecimentos não apenas de administrador, mas, sobretudo, dos princípios a serem seguidos pelos senhores no governo de seus cativos.

Assim, a partir de junho de 1847, inicia a publicação, no Auxiliador da Indústria Nacional, periódico da Sociedade Auxiliadora da Indústria Nacional, da qual Werneck era membro destacado, da sua "Memória sobre a fundação de uma fazenda na Província do Rio de Janeiro, sua administração e épocas que se devem fazer as plantações, suas colheitas, etc. etc.”.

Fosse porque a imprevisibilidade da produção agrícola impusesse certa distância entre teoria e prática, fosse porque os tempos já eram outros, o fato é que quando se tratou da administração do legado deixado por sua comadre e tia, D. Inácia Delfina Werneck (1771-1858), o Barão do Pati do Alferes enfrentou uma série de dificuldades. É nesse ponto, muito mais do que na dinâmica dos laços de parentesco que uniam os dois personagens, que se baseia uma das duas histórias reconstituídas por Sandra Lauderdale Graham, em seu livro voltado ao estudo de casos de mulheres da sociedade escravista brasileira.

Solteira e analfabeta, D. Inácia Delfina possuía, por ocasião da feitura de seu testamento, sete escravos, dos quais dois africanos, e três escravas, todas nascidas no Brasil. Além dos cativos, reunia uma soma razoável de recursos 
em dinheiro e jóias. Nem mesmo o fato de D. Inácia não saber ler ou escrever parece ter surpreendido Sandra Graham, ocupada em reconstituir-lhe a história de vida. Afinal, tratava-se de situação comum a mulheres de igual condição social da mesma geração que $\mathrm{D}$. Inácia, partilhada também por sua irmã, D. Francisca. Inusitado, porém, principalmente ao observador de hoje, foi o fato de a proprietária deixar todos os seus bens a Bernardina e seus cinco filhos. Bernardina fora escrava de D. Inácia, de quem recebera a alforria com a obrigação de servi-la enquanto fosse viva. Dentre outros bens com que era contemplada no testamento, coube a ela dois escravos que a deveriam servir pelo prazo de dois anos, findos os quais, estariam livres.

Seus cinco filhos foram alforriados na pia batismal, e, à época da confecção do testamento, alguns eram menores e outros já haviam alcançado a maioridade. Os bens foram distribuídos desigualmente entre a prole de Bernardina, cabendo, por exemplo, a uma das filhas, Maria, a quantia necessária para quitar o valor de uma escrava que já possuía, de nome Inês. Antes disso, fato incomum, já havia contemplado outra filha de Bernardina, Rosa, com uma escrava de nome Helena.

Dadas as peculiaridades do sistema de herança no Brasil — herdado de Portugal e mantido após a Independência —, que assegurava às mulheres participação na herança deixada pelos pais e maridos, e dada a vigência de relações eminentemente privadas entre senhores e escravos, deixando, pelo menos em princípio, ao arbítrio dos proprietários todas as decisões que dissessem respeito à sua propriedade sobre cativos, a história de D. Inácia não surpreenderia tanto, exceto por instituir como herdeira uma sua ex-escrava.

A decisão, no entanto, assumiu uma série de desdobramentos, decerto não previstos pela testadora, conforme nos mostra Sandra Graham, sendo o principal deles resultado do equívoco na avaliação do montante do espólio. Assim, feitas as doações aos legatários nomeados por D. Inácia, a maioria composta por familiares, o que restou para a liberta Bernardina foram apenas dívidas. Dívidas cuja administração caberia ao primeiro testamenteiro, o Barão do Pati do Alferes. E aqui, não lhe parece ter valido a larga experiência como administrador de terras e escravos, registrada para a posteridade nas páginas do Almanack Laemmert, uma vez que "agiu com discernimento questionável" ao impor à família de Bernardina um contrato de arrendamento de terras exauridas e a preços exorbitantes (p.193).

O leitor desta resenha deve estar se perguntando o que a história de D. Inácia tem em comum com a da escrava Caetana, cuja história, afinal, dá título ao livro, apesar de ocupar menos páginas do que as da filha da aristocra- 
cia cafeeira. Deixemos a autora falar: "São histórias diferentes, sem conexão uma com a outra, exceto no importante sentido de que pertenceram à mesma cultura, sociedade e economia gerais - e que as utilizo para iluminá-las" (p.11). E certamente, é nesse ponto que reside uma das principais qualidades da obra. Laura Graham procura, com sucesso, dar conseqüências à afirmação, inúmeras vezes repetida, mas nem sempre levada em conta, de que "história é contexto". Por isso mesmo, reconstitui minuciosamente os aspectos econômicos, sociais e demográficos de duas importantes regiões cafeeiras, o Município de Vassouras, no Rio de Janeiro, e Rio Claro, em Paraibuna, na Província de São Paulo.

Rio Claro é, assim, o cenário da primeira história narrada, a da escrava crioula Caetana. Tendo como fio condutor da narrativa a recusa de Caetana a partilhar o leito conjugal com seu marido, o também escravo Custódio, Laura Graham aponta como foram complexos os arranjos societários e pessoais que se forjaram no contexto das grandes unidades plantacionistas — ainda que com o emprego do termo não se queira repetir o engano de supor que essas unidades constituíssem verdadeiras autarquias. Tais arranjos se expressavam desde as pretensões do marido legítimo de Caetana a reproduzir, com anuência da família da escrava, uma relação de tipo patriarcal, forçando-a a submeter-se, até as possibilidades encontradas por Caetana em manipular sua condição de escrava doméstica, de mucama das mulheres da família na casagrande para convencer a seu senhor, Capitão Tolosa, o mesmo que a constrangeu ao casamento, a intermediar sua demanda pela anulação do enlace.

Decisão que o fazendeiro aceita, mas não sem antes consultar um de seus pares, hóspede ocasional em sua casa, Manuel da Cunha de Azeredo Souza Chichorro. Antigo Secretário de Governo de São Paulo que, no cargo, se ocupou de questões como a utilização de homens vadios, malfeitores e vagabundos para estabelecerem povoações no sertão, colaborador da Revista do IHGB, Manuel da Cunha Chichorro o aconselha a atender aos rogos da escrava, mostrando assim que se as decisões dos senhores se circunscreviam ao âmbito privado, elas não correspondiam apenas ao arbítrio ou aos caprichos do proprietário.

O desfecho do pleito de Caetana, intermediado por seu senhor, é conhecido: a Cúria Metropolitana da Bahia recusa-lhe a anulação uma vez que a seu caso não era aplicável nenhuma das disposições canônicas que previam a anulação. Esse resultado decepciona mais o leitor do que a impossibilidade, assumida pela autora, de explicar as razões íntimas ou as menos recônditas, como se queira, que levaram Caetana a rejeitar o "estado de casada". Isso porque 
Laura Graham se preocupa o tempo todo - e essa é outra característica positiva do trabalho - em formular hipóteses consistentes, numa espécie de 'maiêutica socrática' muito mais esclarecedora do que se fossem dadas respostas definitivas.

Um outro aspecto a ressaltar é o de que a perspectiva adotada é a da história de gênero, o que justifica o fato de personagens masculinos ocuparem papel proeminente na reconstituição das tramas. A preocupação central, portanto - apesar de o subtítulo informar que se trata de "Histórias de mulheres da sociedade escravista" - é com a análise relacional, realçando a instabilidade dos papéis sociais assumidos por homens e mulheres no Brasil escravista.

Em meio a temas abrangentes - como organização da Guarda Nacional, atuação dos juízes de Paz, laços de compadrio, família escrava, recolhimentos no Brasil, rebeliões de escravos, sistema de herança, alianças matrimoniais, ilegitimidade, irmandades religiosas, Revolução Liberal de 1842 e declínio da cafeicultura no Vale do Paraíba no Rio de Janeiro a partir da experiência concreta de um fazendeiro - Laura Graham desvenda a interação entre as histórias de Caetana, Chichorro, Tolosa, D. Inácia, Bernardina e seus filhos e o Barão do Pati do Alferes.

Caetana diz não foi lançado nos Estados Unidos três anos antes de a tradução vir a público no Brasil (Caetana says no: women's stories from a Brazilian slave society. New York: Cambridge Press, 2002) sendo objeto de resenhas em revistas especializadas como Hispanic American Historical Review e The Americas. O livro integra, naquele país, a coleção "New approaches to the Americas", editada por Stuart Schwartz.

Trata-se de obra elaborada com base em uma extensa pesquisa primária, constituída de fontes censitárias, cartorárias e eclesiásticas, perscrutada de maneira original. Mas há um aspecto que realmente deve surpreender nosso leitor: a opção da autora por basear-se em obras produzidas sobre a escravidão brasileira por especialistas norte-americanos. É bem verdade que muitos deles sobejamente conhecidos no Brasil, como no caso dos trabalhos de Stuart Schwartz e outros aqui radicados - Robert Slenes, por exemplo - e contra os quais a autora não poupa críticas: ao primeiro, por defender a centralidade do trabalho para o entendimento da dinâmica da sociedade escravista em oposição a fatores como família, comunidade e religião (p.49); ao segundo, por exagerar na insistência com que os senhores estimulavam seus escravos a se casarem com o fim de controlá-los enquanto cativos (p.56).

Não que estejam ausentes algumas das mais representativas obras pro- 
duzidas pela nossa academia, mas nesse aspecto, a pesquisa sobre os títulos que poderiam lançar luz sobre o tema abordado não é, nem de longe, exaustiva. Assim, talvez se encontre aí uma outra originalidade do trabalho, da qual o leitor deva extrair algumas conseqüências: a de que se trata de uma abordagem, em boa medida, construída a partir do olhar do especialista estrangeiro, certamente influenciado pela própria compreensão da dinâmica de um país também de passado escravista.

Tal opção, em determinadas passagens, permite que se estabeleçam comparações importantes, ainda que implícitas, com o contexto da América do Norte. Esse parece ser o caso em que a autora reconhece que a precária legitimidade dos senhores sobre seus escravos no Brasil baseou-se na reiteração do direito costumeiro, dispensando, ao contrário do que se observou no norte da América, a produção de um discurso baseado na inferioridade racial (ainda que, vale ressaltar, esse não estivesse de todo ausente, sobretudo no Brasil Imperial). Ou quando afirma que a cultura da sociedade brasileira, por sua herança ibérica, era essencialmente jurídica — no sentido de que a maioria das transações eram autenticadas por documentos legais — diferentemente do que se verificava nos domínios coloniais das metrópoles da Europa Central (p.117-8).

A obra de Laura Graham, por fim, cumpre bem o programa da microhistória, vertente à qual se filia, com o mérito de preencher os vazios entre o particular e o geral, entre as trajetórias individuais e as coletivas, ampliando a aplicação do método para além da história cultural e das mentalidades. 